\title{
Erratum
}

\section{Erratum: Chen et al., QRFP and Its Receptors Regulate Locomotor Activity and Sleep in Zebrafish}

In the article "QRFP and Its Receptors Regulate Locomotor Activity and Sleep in Zebrafish" by Audrey Chen, Cindy N. Chiu, Eric A. Mosser, Sohini Kahn, Rory Spence, and David A. Prober, which appeared on pages 1823-1840 of the February 10, 2016 issue, several errors were discovered and have been corrected below. These corrections do not affect the main conclusions and interpretation of the paper. They have been corrected in the online PDF version.

Author line: The fourth author's surname was misspelled. The corrected author line is:

Audrey Chen, Cindy N. Chiu, Eric A. Mosser, Sohini Khan, Rory Spence, and David A. Prober

Figures 6 and 7

There were three formatting errors accidentally introduced in both Figure 6 and Figure 7. In both figures, the label $E^{\prime}$ appears in panel $A$, but should be in panel $A^{\prime}$ and the label $F^{\prime}$ appears in panel $C$, but should be in panel $C^{\prime}$. In addition, in the schematic diagram in the bottom left corner of each figure, there are three arrows that indicate rostral (r), caudal (c), and lateral (I) axes. The " $c$ " is located below the " $r$ ", but should be located to the right of the arrow pointing right.

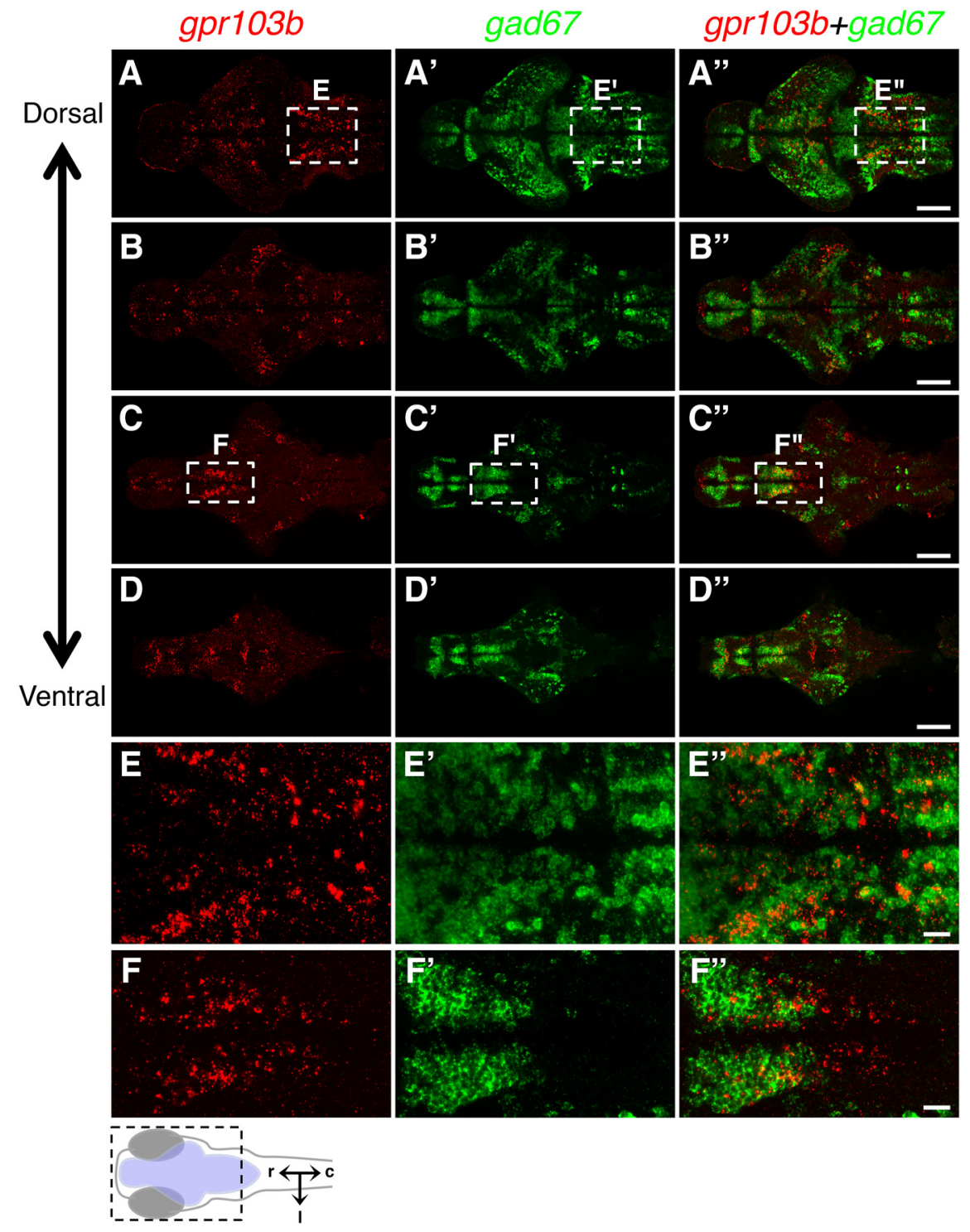

Figure 6. 


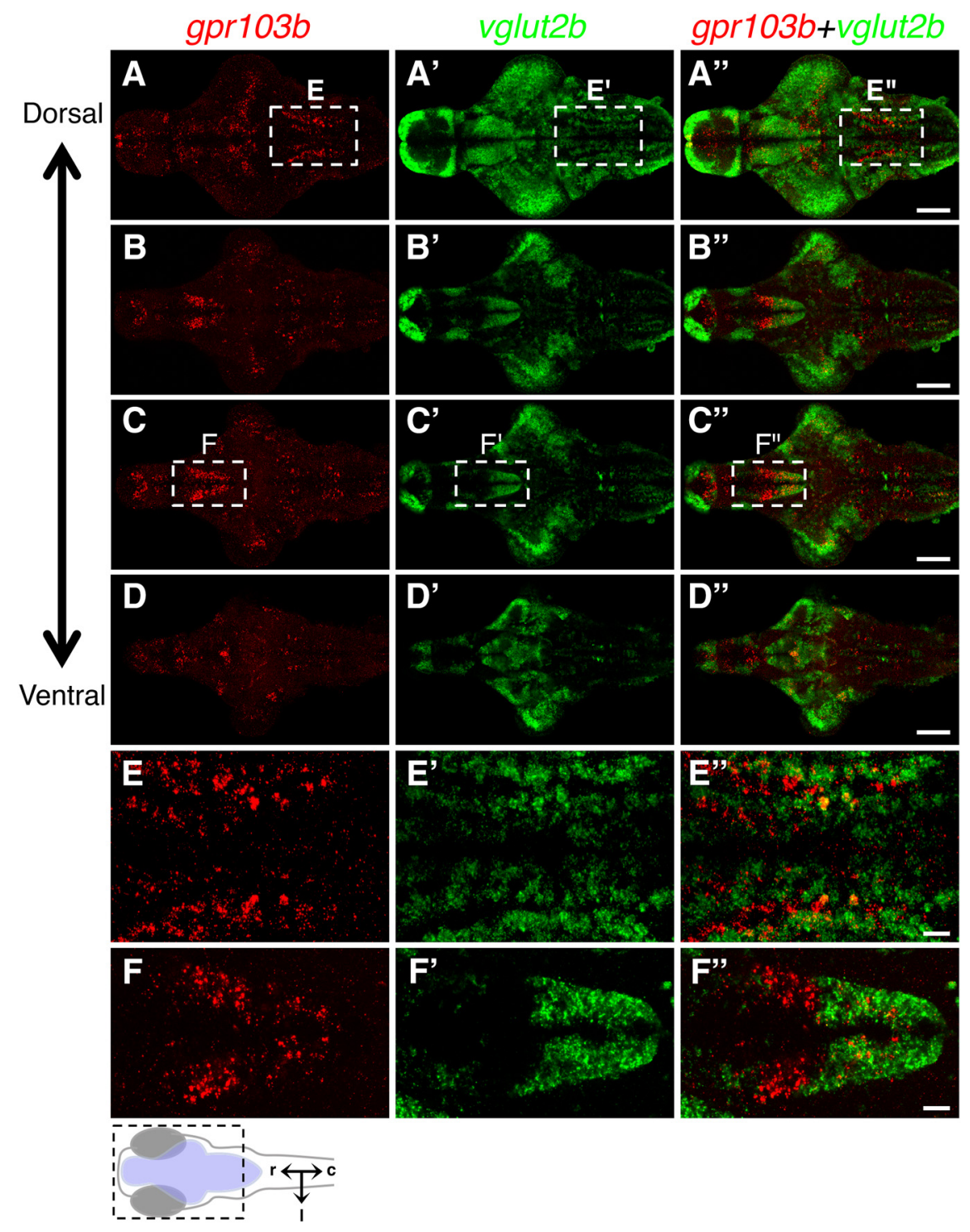

Figure 7.

DOI: 10.1523/JNEUROSCI.1200-16.2016 